\title{
1st International \& 2nd National Orthodontic Conference of Bangladesh Orthodontic Society (BOS) - Brief Report
}

Hossain $\mathrm{MZ}^{1} \mathrm{BDS}, \mathrm{PhD}$

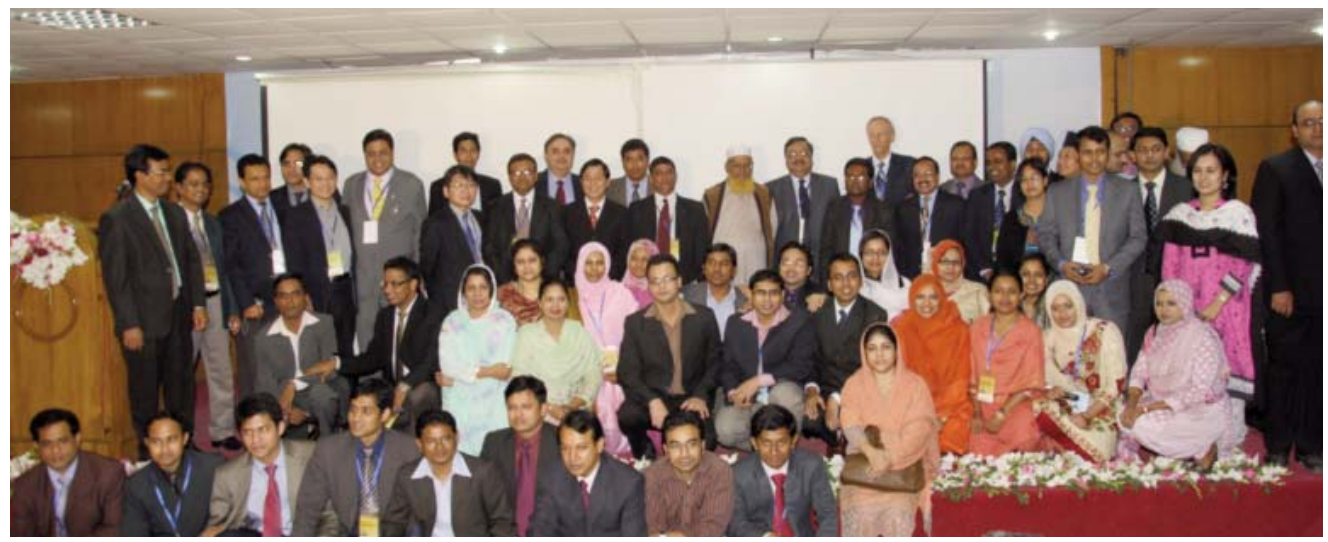

Bangladesh Orthodontic Society (BOS) has successfully organized its 1st International and 2nd National Orthodontic Conference on 27-28th January, 2012. The opening ceremony and scientific session of Conference was held in LGED conference hall, Agargaon, Shere Bangla Nagar \& Pan Pacific Sonarga Hotel, at Dhaka, Bangladesh. 22 International reputed speakers from 7 different countries including Mexico, Singapore, Japan, Taiwan, India, Sri Lanka, Nepal \& host Bangladeshi speakers participated the conference. There were 400 registered participants attended the meeting.

There were 25 oral presentations and 13 poster presentation. Among them President, World Federation of Orthodontists, Prof. Roberto Justus delivered a series of 5 hour lectures titled as follows:

1. Dentofacial Orthopedics - Correction of Class II Div 1 Malocclusions with Severe Skeletal Problems in the Early Mixed Dentition.

2. The Anterior Open Bite: Conservative orthodontic treatment with stability.

3. Methods to Achieve Excellence in Orthodontic TreatmentAmerican Board of Orthodontics' Standards/Criteria/Methods for Approval of Clinical Cases - Clinical application to our practices.

4. Preventing white spot lesions on tooth enamel and diminishing the incidence of bracket bond failures

President, Asia Pacific Orthodontic Society (APOS), Dr. Loh
Kai-Woh delivered one hour lecture titled "Can moving teeth changes faces?" Dr. Johnny Joung-Lin Liaw of (TAO) Taiwan, Dr. Yasso Watanabe of Japan and also speakers from India ( Prof. Nikhilesh R Vaid, Prof. Ashish Gupta, Prof OP Kharbanda), Srilanka, (Dr. WM. Senadeera, Dr. Ratnakumara Dissanayake), from Nepal (Dr. Rabindra Man Shreshtha, Dr. Dashrath Kafle) and host Bangladesh (Prof Zakir Hossain, Dr. Shamim Hassan, Dr. Mostaque, Dr. HM Rizvi, Dr. G. Rabbi). Prof. Zakir briefed the Scenario of Orthodontics \& activity of BOS in his presentation from 1961 to date. The scientific sessions included Poster presentation by many FCPS passed Orthodontists \& FCPS trainees. The scientific sessions covered Orthodontic treatment with Multidisciplinary approach \& newer techniques.

Opening session was presided by Prof. Dr. Md. Emadul Haq, President, BOS and guests of honor was graced by WFO President and APOS President. Secretary General of the organizing committee Prof. Zakir Hossain stated in his inaugural \& welcome speech that, the conference themed as "The New Horizon in Orthodontics" will be a center of excellence for sharing scientific knowledge among the members of participating countries. Our younger trainees will have wider exposure of international expertise. This will in turn upgrade Orthodontic technique, education, treatment delivery in Bangladesh. We are committed to organize such conference annually on regular basis to stay competitive in international arena of Orthodontic education, techniques \& service delivery. All the delegates appreciated the organizing committee for presenting two days conference with very high profile reputed speakers.

${ }^{1}$ Prof. Dr. Md. Zakir Hossain, Secretary General, Bangladesh Orthodontic Society (BOS) and Conference Organizing Committee, Professor \& Head, Department of Orthodontics, Dhaka Dental College 
Both WFO \& APOS president highly appreciated \& congratulated the efforts of BOS for organizing the Conference. WFO president recognized the recent domestic \& international activities including the present scientific conference of BOS. He also urged to be the member of WFO by the qualified Orthodontists $\&$ also encouraged for student membership. He also briefed the e-journal (web based on line journal) of WFO and encouraged all to contribute $\& \log$ on which will start soon. APOS president also appreciated congratulated BOS \& shared his opinion with WFO President.

The closing session was held in Pan Pacific Sonarga Hotel. There was Award Presentation Ceremony and exchange of plaque among the participants which was followed by cultural show \& Banquet dinner.

WFO President handed over his souvenir from Mexico to President \& Secretary General of BOS

President \& Secretary General of BOS awarded honorary membership of BOS to the WFO President, Prof. Roberto Justus for his continuous support for BOS.

President \& Secretary General of BOS awarded honorary membership of BOS to the APOS President Dr. Loh Kai Woh for his continuous support for BOS.

President \& Secretary General of BOS received Plaque of appreciation \& support from Taiwan Association of Orthodontists (TAO) from Vice President, Dr. Johnny Joung-Lin Liaw.

President \& Secretary General of BOS awarded plaque to Taiwan Association of Orthodontists (TAO) for their support for BOS, received by Vice President , TAO, Dr. Johnny Joung-Lin Liaw.

President BOS, Prof Dr. Mohammed Emadul Haq \& Vice President BOS, Prof. Dr. Kazi Abdul Khaleque and Prof. Dr. Md. Zakir Hossain received Plaque for their outstanding performances from BOS. . Plaque of appreciation was also awarded to Editors of APOS publications, Dr, A. Gupta and Dr, NR Vaid by president \& secretary general of BOS. On behalf of APOS publications a plaque of appreciation was also presented to BOS, to recognize the BOS activities. It may be also mentioned that the conference news was widely covered by prominent daily news paper of Bangladesh.

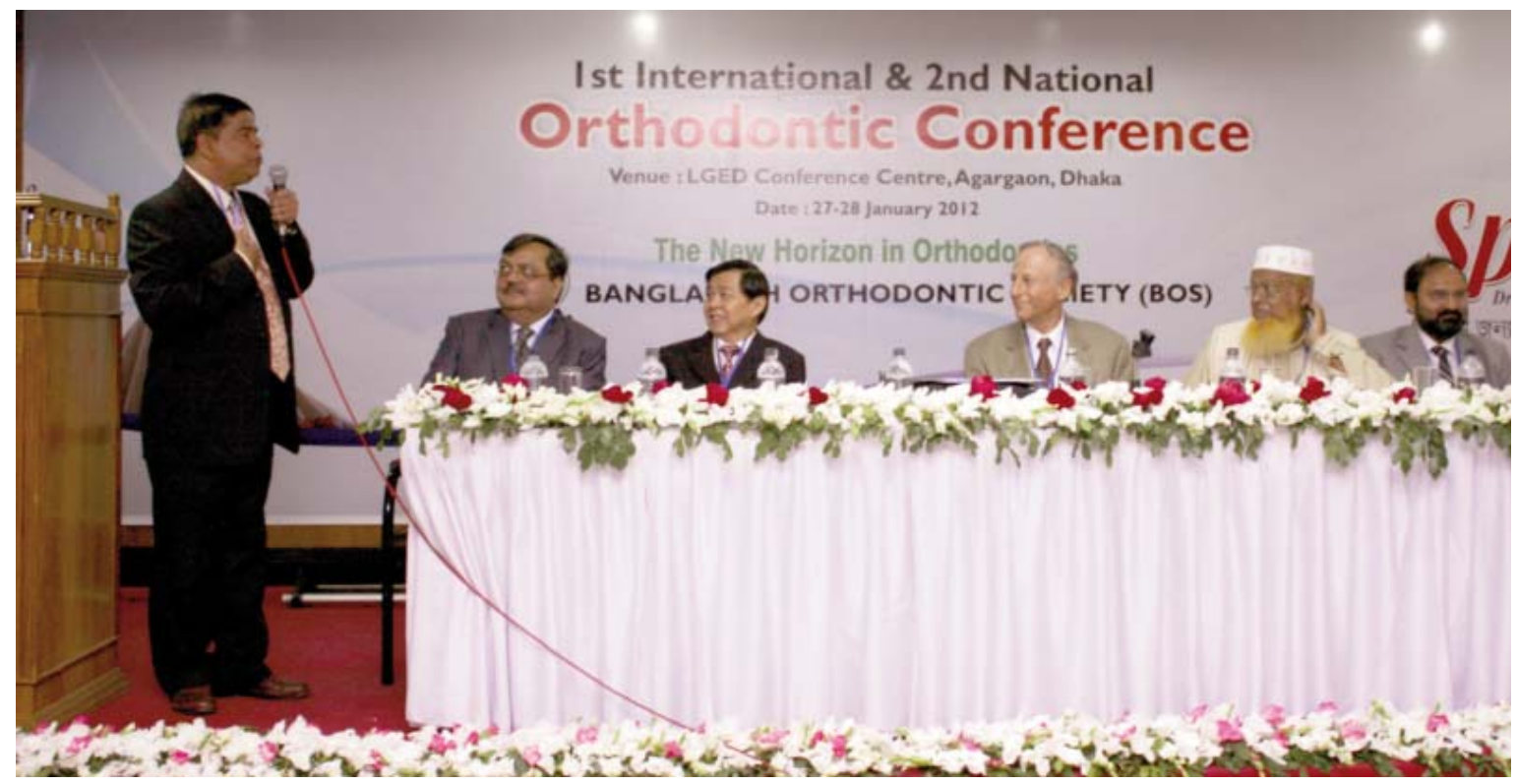

PHOTO OF INAUGURAL SPEECH AT BOS MEETING

Dr. Md. Zakir Hossain, secretary-general of the Bangladesh Orthodontic Society (BOS) and the conference organizing committee makes his inaugural speech at the 1st International and 2nd National Orthodontic Conference of the BOS in January in Dhaka, Bangladesh. He was joined by Dr. Om. Prakash Kharbanda of India, guest of honor; Dr. LOH Kai Woh, special guest as president of the Asian Pacific Orthodontic Society; Dr. Roberto Justus, chief guest as president of the WFO; Dr. Md. Emadul Haq, president of the BOS and the conference organizing committee; and Dr. Iqbal Hossain, guest of honor. 


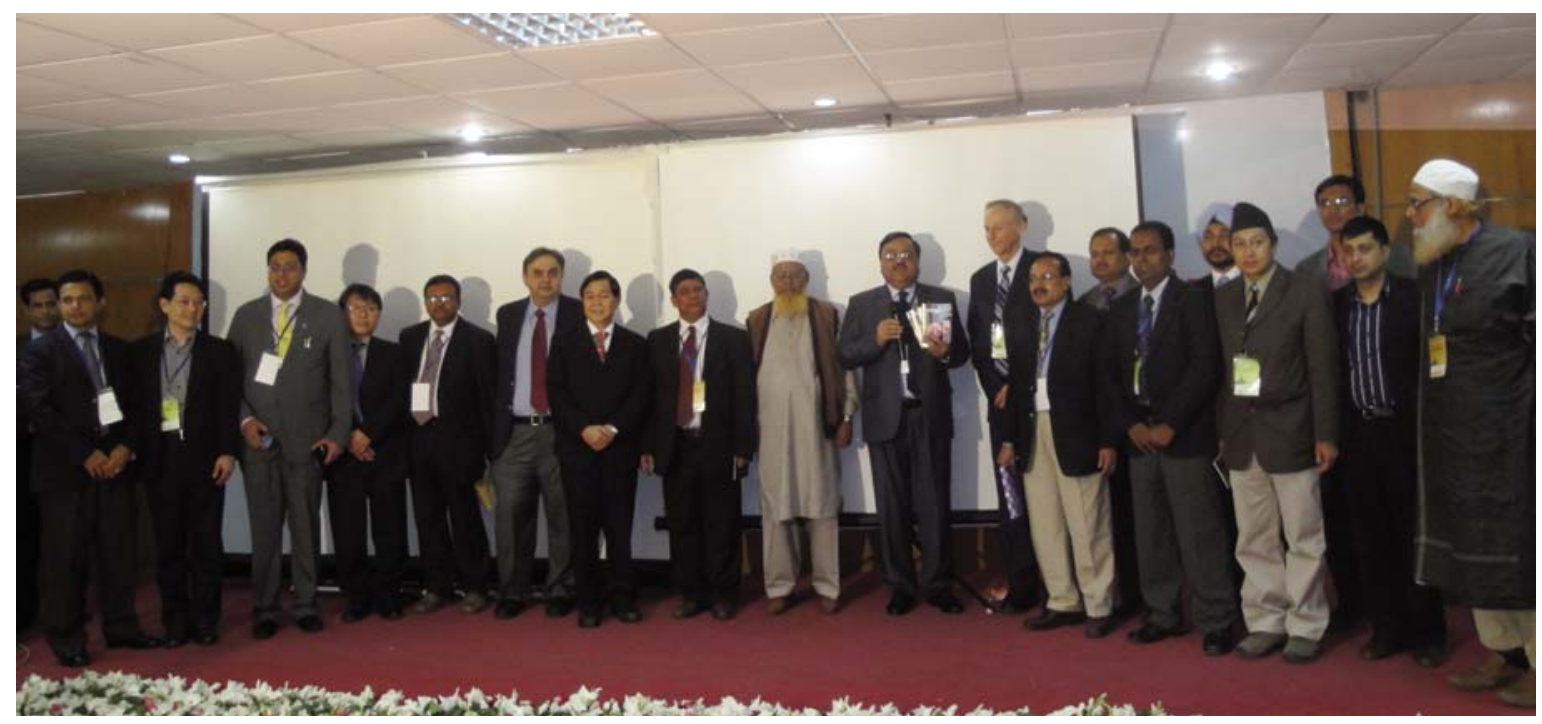

BOS Executives with International deligates

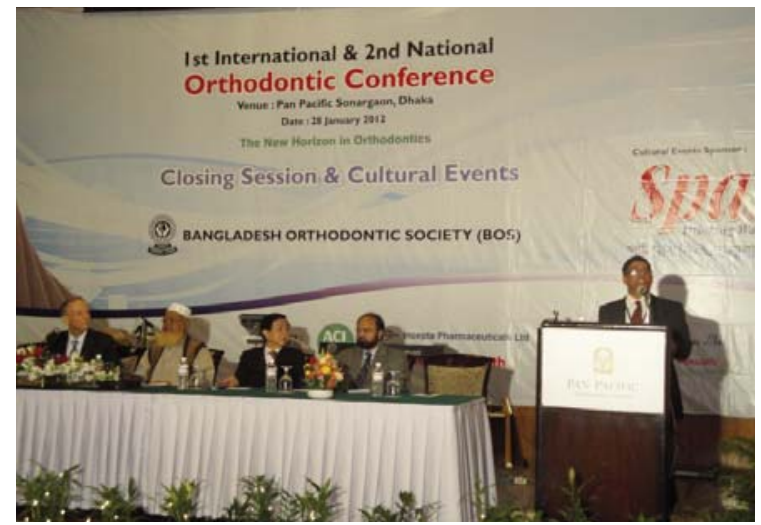

Closing Session at Panpacific Sonarga Hote

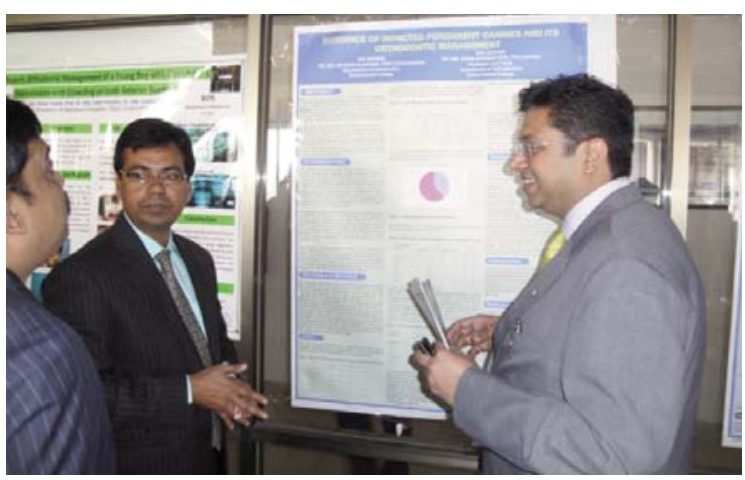

Dr. Mahboob Alam facing Prof. Ashish \& Dr. Saifuddin in Poster Evaluation

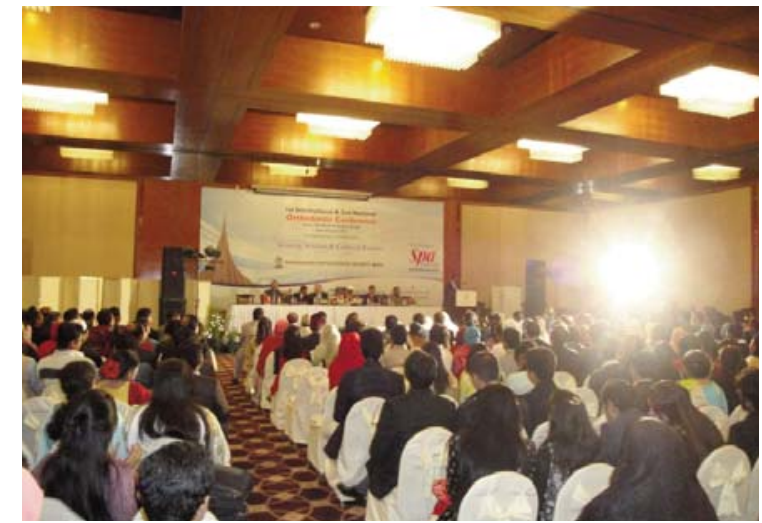

Closing session in PanPacific Sonarga Hotel

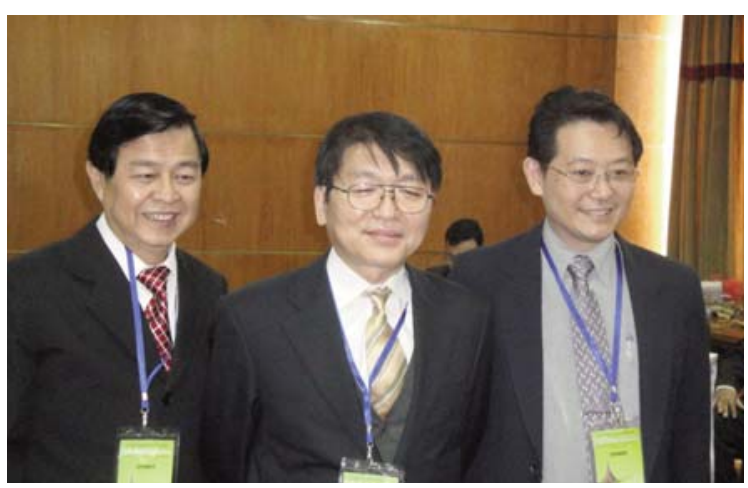

Dr. Loh Kai Woh of Singapore, Dr. Watanabe of Japan and Dr. Liaw of Taiwan, 


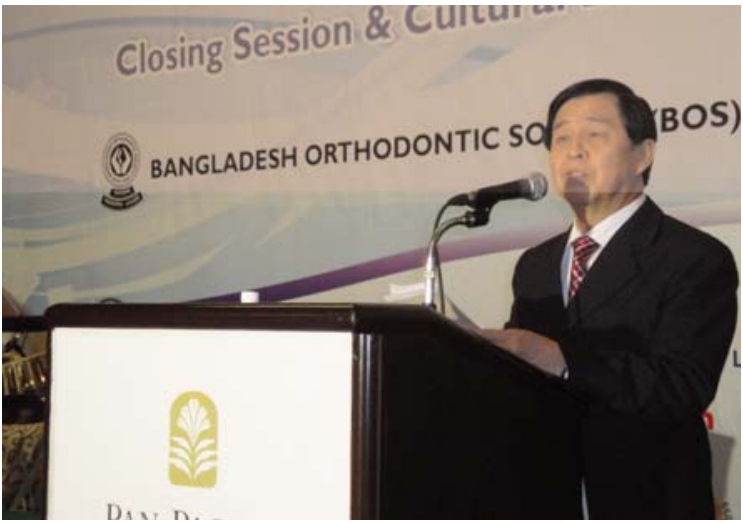

Dr. Loh, President APOS in closing Session

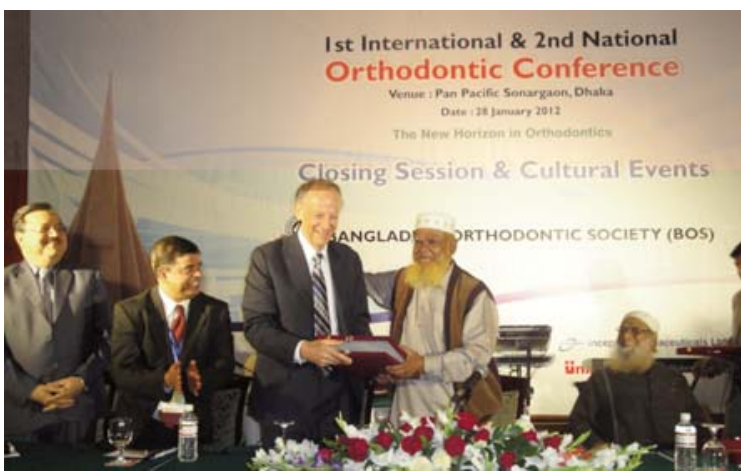

Honarary membership of BOS awarded to Prof Roberto Justus, President WFO

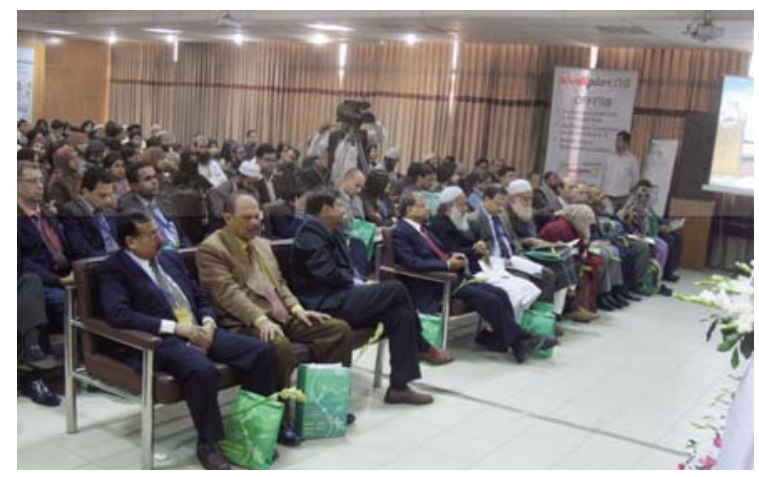

Partial view of Scientific Session

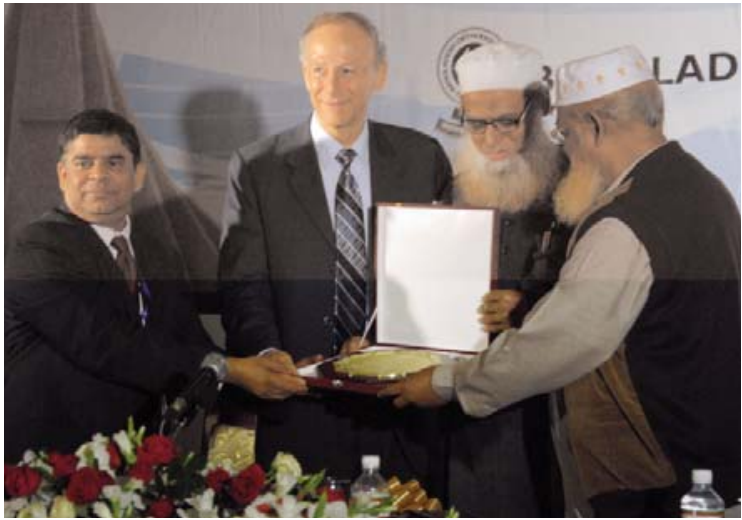

Honarary BOS membership awarded to WFO president

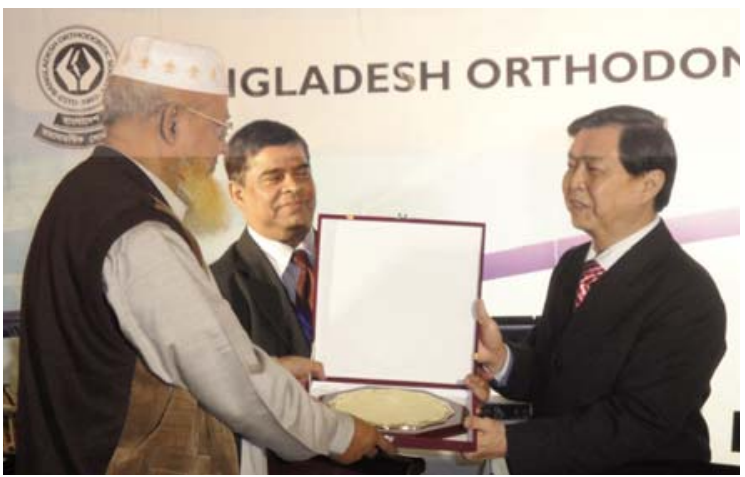

Honarary Membership of BOS is awrded to Dr. Loh Kai Woh, President APOS

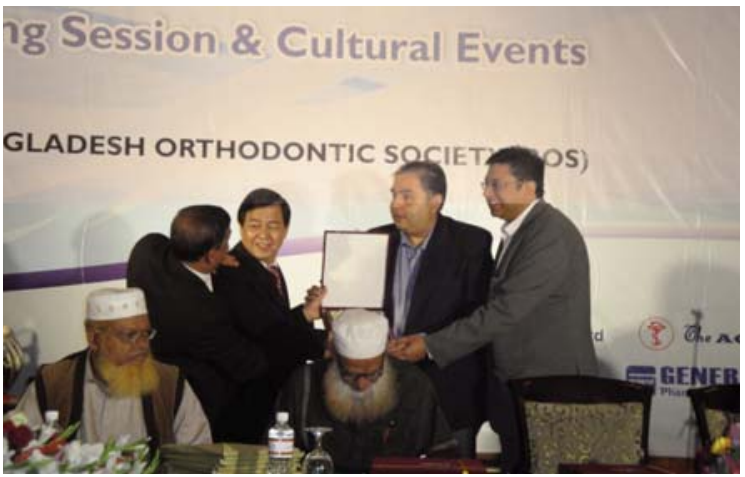

Plaque of appreciation given to APOS publication by BOS 


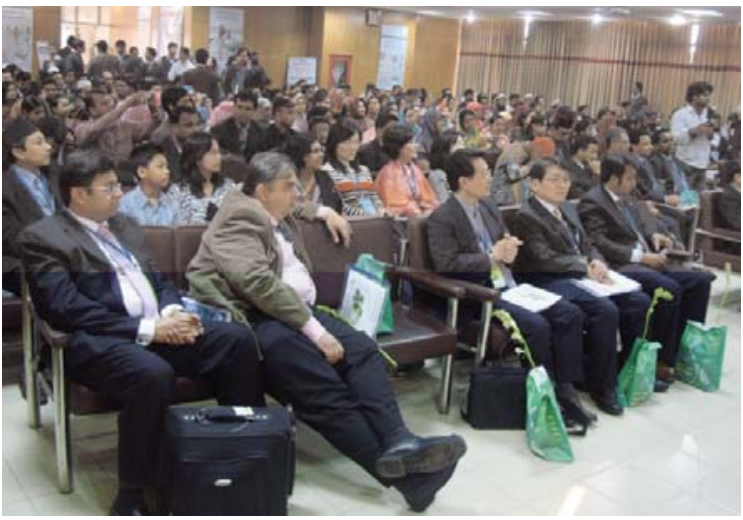

Partial view of a Scientific session

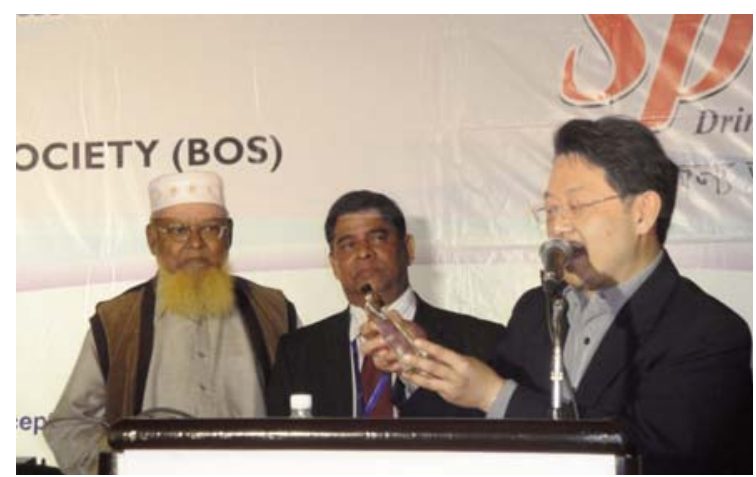

Plaque of appreciation given to BOS by TAO from Dr. Liaw, Vice President TAO

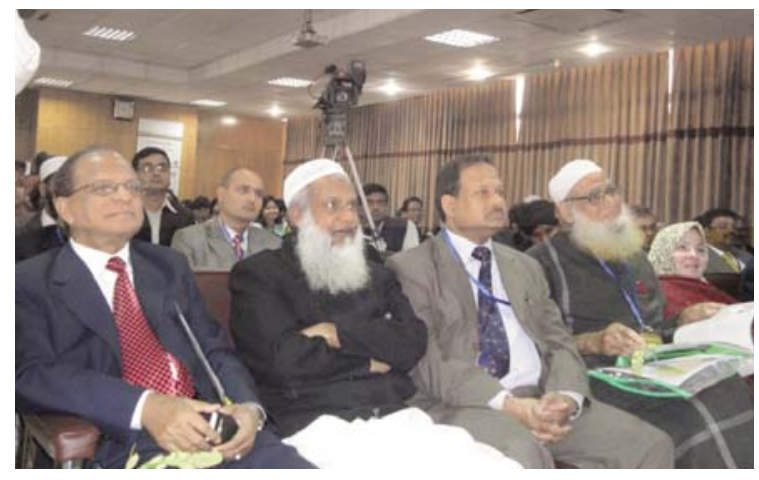

Prof. Ashraf, Prof. Mehdi, Dr. Gazi, Prof. Khaleque \& Prof. Aziza

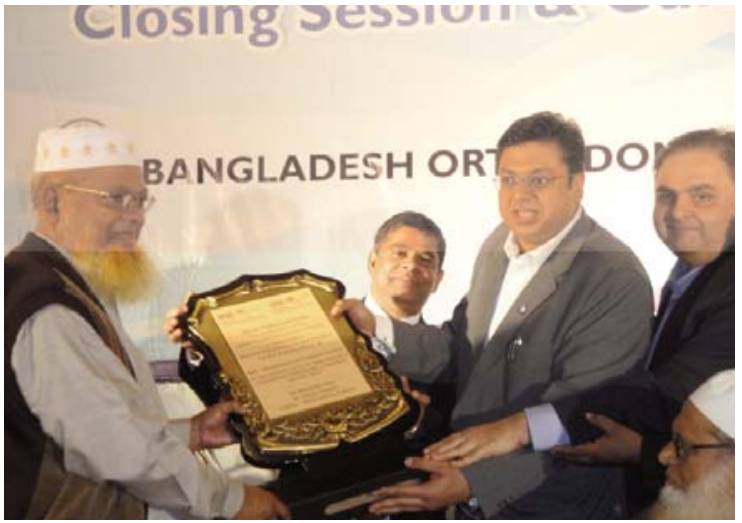

Plaque of Appreciation given to BOS by APOS Publcation

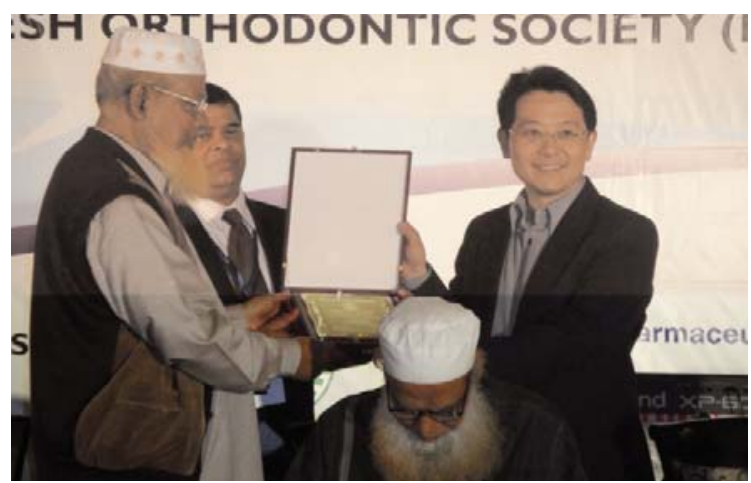

Plaque of appreciation given to TAO by BOS, recived by Dr. Liaw

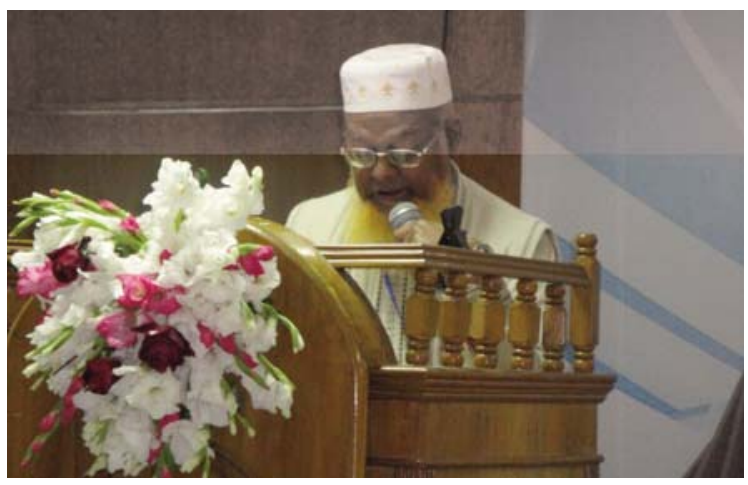

Prof. Emadul Haq, President BOS 


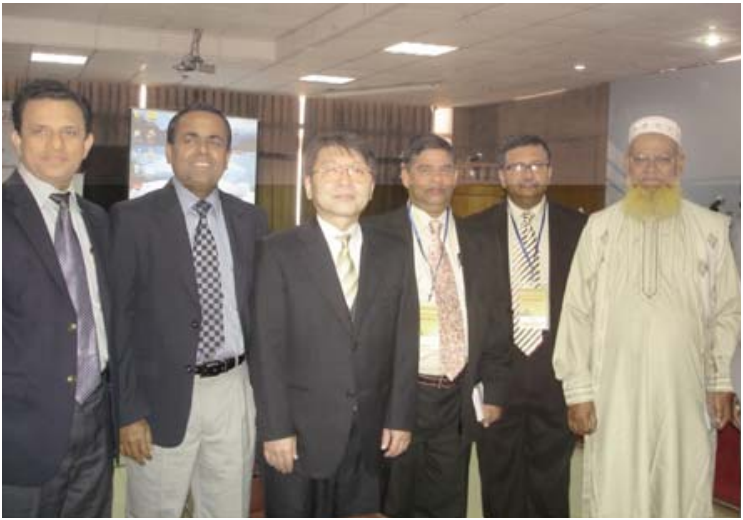

Prof. Haq, Dr. Sattar, Dr. Zakir, Dr. Watanabe, Dr. Senedara, Dr. Ratna Kumara

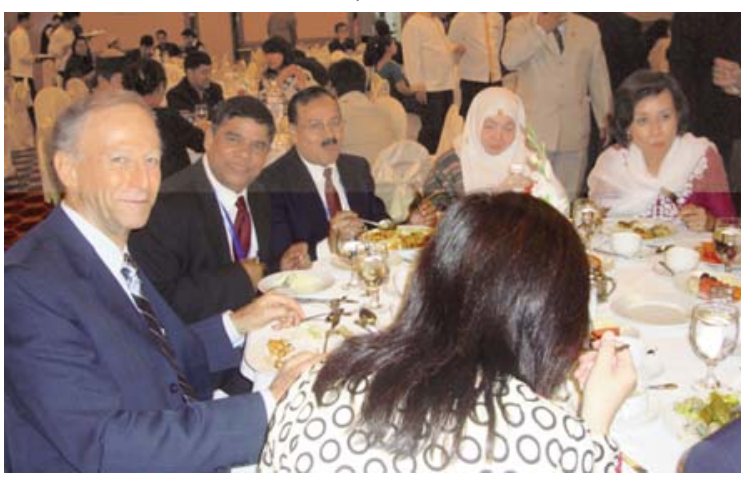

Prof. Roberto in Gala Dinner with Prof Aziza Begum \& Dr. Lynden

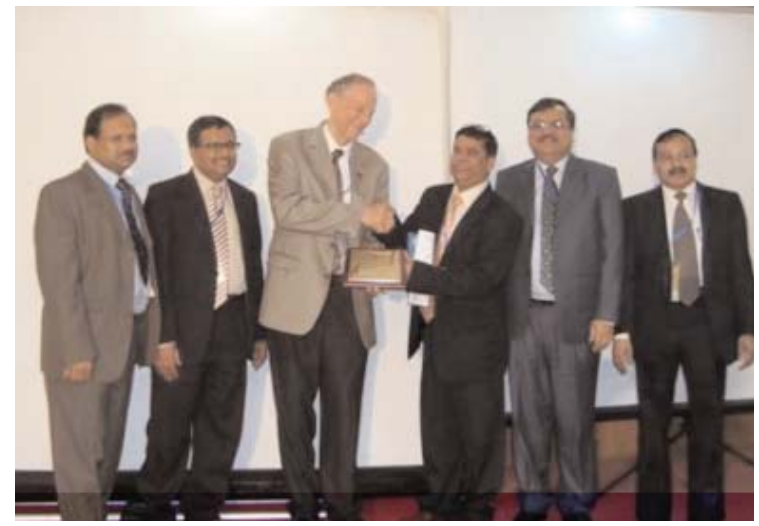

Prof. Roberto, Prof. Kharbanda with Conference organizing Secretary, Chairman Scientific comitee, Joint Secretary and Treasurer

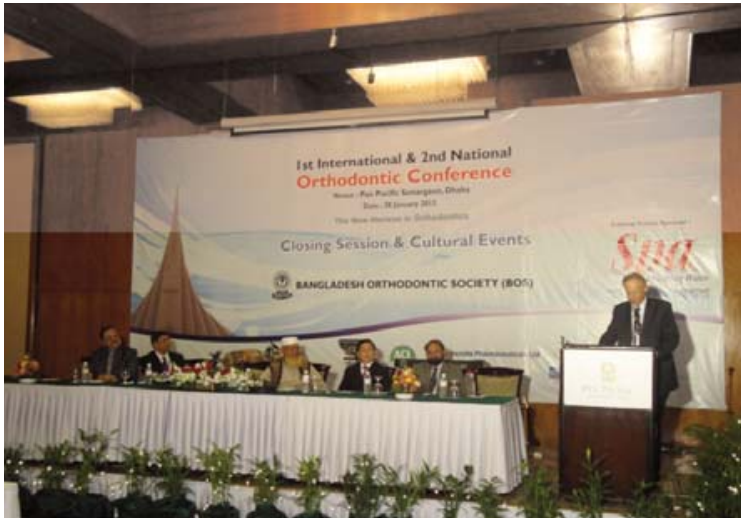

Prof. Roberto , President WFO, in Closing Session

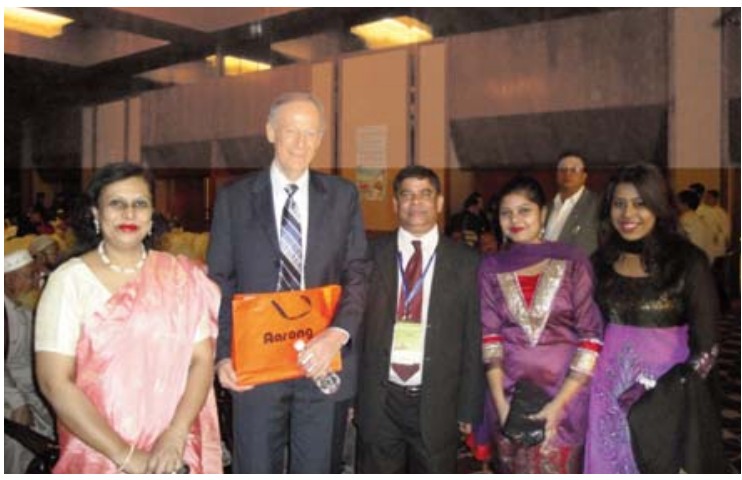

Prof. Roberto with Dr. Zakir and Dr. Sabrina

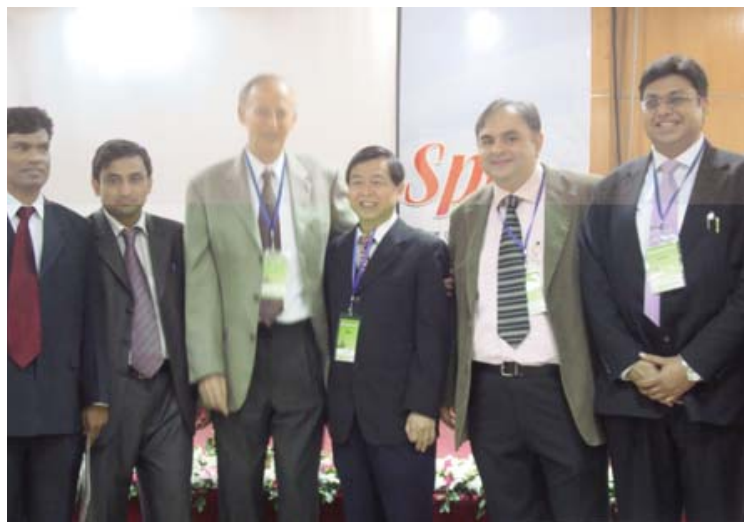

Prof. Roberto with Prof. Nikhilesh, Prof. Ashish, Dr. Loh Kai Woh, Dr. Mamun and Dr. Rashed 


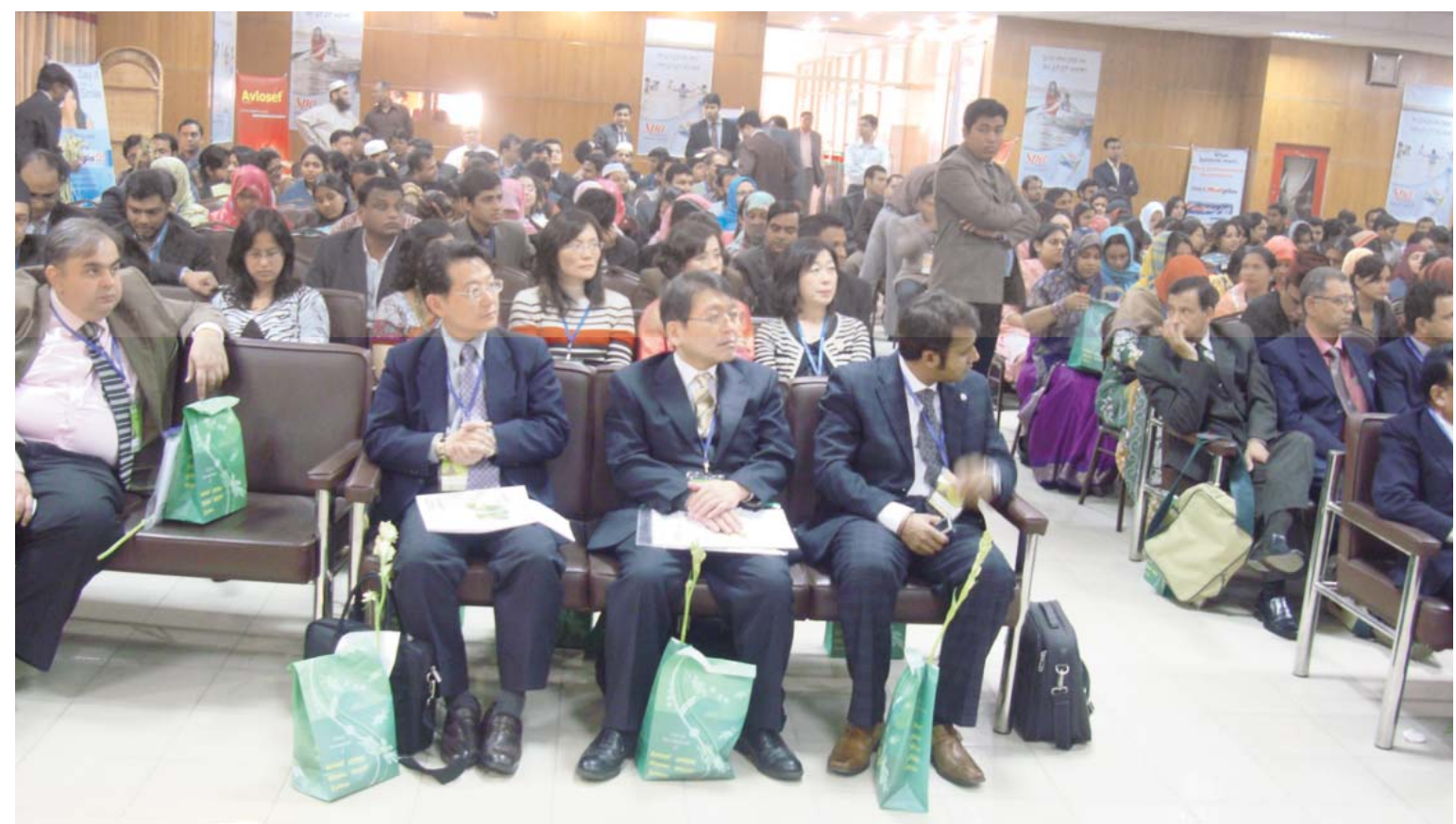

Partial view of Scientific Session

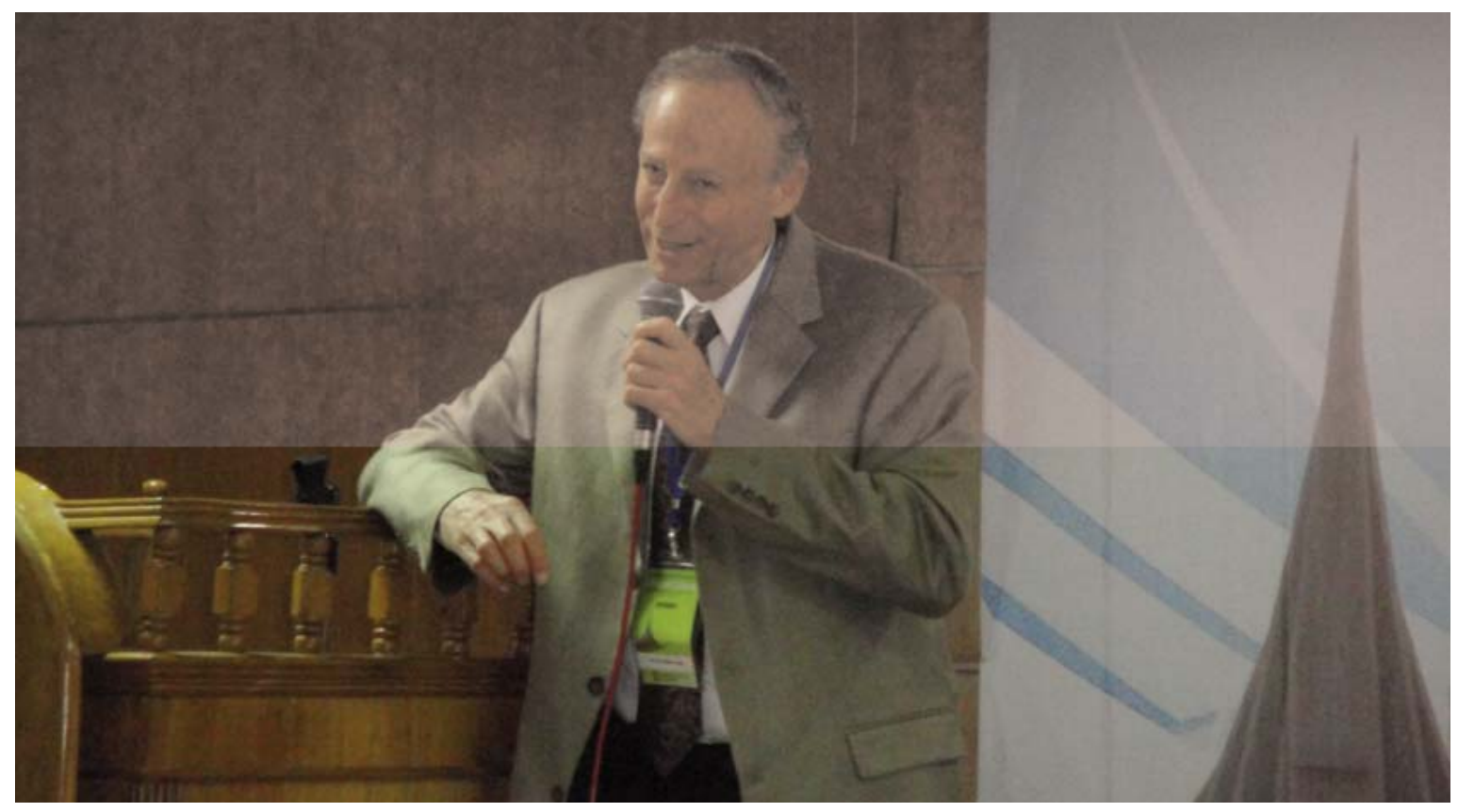

Prof. Roberto, WFO President

BOS Members are very lucky lucky lucky to have a very high profile speaker and WFO President Professor Roberto Justus that made young orthodontics more devoted in this speciality 